\title{
Body composition of rats in B-vitamin deficiencies
}

\author{
By K. GUGGENHEIM AND E. J. DIAMAN'T \\ Laboratory of Nutrition, Department of Biochemistry, Hebrew \\ University-Hadassah Medical School, ferusalem, Israel
}

(Received I6 Fune 1958)

In a previous publication (Guggenheim \& Halevy, I958) it was reported that rats deficient in pyridoxine, thiamine, riboflavin or pantothenic acid have a higher liver nitrogen content per $100 \mathrm{~g}$ body-weight than either ad lib.- or pair-fed controls. Since in normal rats liver nitrogen per unit body-weight decreases with increasing age and weight, and since the deficient animals lagged behind both controls in weight increase, levels of liver nitrogen of deficient rats were compared with those of animals of equal weight maintained on a full diet offered ad lib. Liver nitrogen per unit body-weight was found to be diminished in thiamine-deficient rats, to be increased in riboflavindeficient animals and not to be significantly changed in rats deficient in pyridoxine or pantothenic acid. The question, therefore, arose whether the changes observed in liver nitrogen are an expression of more profound changes in composition of the liver or even of the whole body.

Increased protein content has been found in livers of rats treated with cortisone (Silber \& Porter, 1953; Clark \& Pesch, 1956). Evidence of involvement of the adrenals in deficiencies of pyridoxine, riboflavin and pantothenic acid has accumulated during recent years (Morgan, I951 ; Ershoff, 1952 ; Forker \& Morgan, I 954; Guggenheim, I954a; Guggenheim \& Diamant, 1955; Eisenstein, 1957). The compositions of liver and carcass of adrenalectomized and of cortisone-treated rats were therefore studied for comparison.

\section{METHODS}

Young male rats were used throughout.

The basal diet consisted of casein (vitamin-free) i8, glucose 37 , maize starch 36 , vegetable oil 5 , and salt mixture (U.S.P. XIII) 4 parts. 'This diet was supplemented, in $\mathrm{mg} / \mathrm{I} 00 \mathrm{~g}$ ration, with thiamine 0.2 , riboflavin 0.3 , pyridoxine 0.1 , calcium pantothenate $1 \cdot 6$ and choline chloride 100 . Each rat received roo i.u. vitamin A and 4 i.u. vitamin $\mathrm{D}$ twice weekly. For production of pyridoxine, thiamine, riboflavin or pantothenic-acid deficiency the relevant vitamin was omitted from the normal diet. To each $\mathrm{kg}$ of the corresponding vitamin-free diet $20 \mathrm{mg}$ deoxypyridoxine or $50 \mathrm{mg}$ galactoflavin or $15 \mathrm{mg}$ of the calcium salt of $\omega$-methylpantothenic acid were added. Specific signs of deficiency appeared after 4-5 weeks in pyridoxine- and thiamine-deficient rats, and after 6-8 and 7-9 weeks in rats deficient in pantothenic acid or riboflavin, respectively. Control animals received the supplemented basal diet offered ad lib. or restricted in amount, according to the quantity of food consumed by the deficient rats. 
Since rats intended for experiments on thiamine and pyridoxine deficiencies had a similar initial weight, and since they happened to eat similar amounts of food, the results obtained with the pair-fed control rats of these two groups were treated as for one group.

Bilateral adrenalectomy was performed in a single operation under ether anaesthesia. The animals were offered a $\mathrm{I} \%(\mathrm{w} / \mathrm{v}) \mathrm{NaCl}$ solution instead of tap water and were examined 8-10 days after operation. The hormone preparation used was cortisone acetate (Cortadren, Schering Corporation).

The animals were killed with pentobarbital. After depilation with barium sulphide the liver was removed and examined separately and the carcass was carefully cleaned of intestinal contents and blood. Livers and carcasses were dried to constant weight for determination of water content and then extracted with ether in a Soxhlet apparatus for determination of body fat. Nitrogen in fresh livers and in fat-free, dried, ground carcasses was determined by the Kjeldahl method

\section{RESULTS \\ Effects of vitamin deficiencies (Table $\mathbf{I}$ )}

Pyridoxine. Livers of pyridoxine-deficient rats (group I) were considerably enlarged. They contained significantly more nitrogen per unit body-weight than those of ad lib.- or pair-fed animals of the same age (groups 3 and 5) and even a little more than those of the pair-weight controls (group 4), although these were younger. The greater part of the total body nitrogen was, therefore, accumulated in the livers of the deficient rats, i.e. $6 \cdot 7 \%$ as against $4 \cdot 1,4 \cdot 4$ and $5.8 \%$ in livers of pair-fed, ad lib.-fed and pairweight controls. Further, both liver and carcass fat had diminished in this vitamindeficiency state.

Thiamine. In contrast to pyridoxine-deficient rats, thiamine-deficient animals (group 2) had relatively smaller livers, and the level of liver nitrogen/roo g bodyweight was lower than that of the pair-weight controls. No shift was observed of body nitrogen to the liver, and the livers contained almost the same percentage of body nitrogen as those of the ad lib.- and pair-fed animals and significantly less than those of the younger pair-weight rats. Liver and carcass fat were likewise decreased.

Riboflavin. In this deficiency too (group 6), the liver was much enlarged and the level of its nitrogen per unit body-weight considerably increased. It was even higher than that of the much younger pair-weight controls. The livers contained as much as $8.7 \%$ of the total body nitrogen, which was more than twice the percentage found in ad lib.-fed controls (group 9). The concentration of liver fat was almost normal, whereas that of the carcass was much reduced.

Pantothenic acid. These rats (group ro) likewise had enlarged livers with an increased nitrogen content per unit body-weight. It approximated to that of the much younger pair-weight controls (group 8). Again, there was a shift of body nitrogen to the liver, which contained a significantly higher percentage of body nitrogen than in the ad lib.and pair-fed controls (groups II and I2). Fat contents of both liver and carcass were much decreased. 


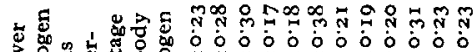

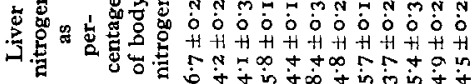

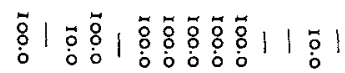

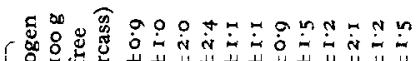

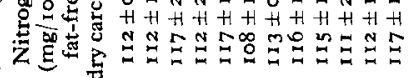

象

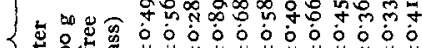

$3 \frac{1}{00}$

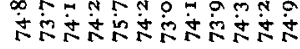

ม八

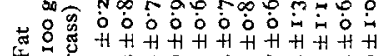

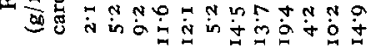

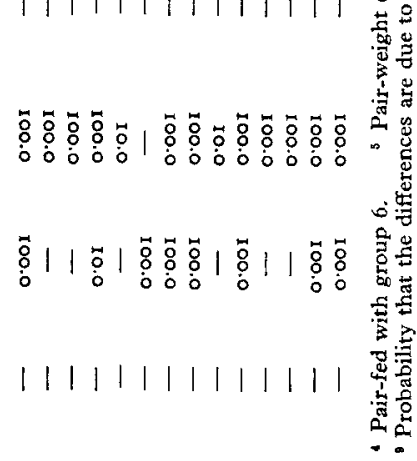

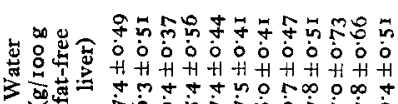

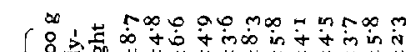

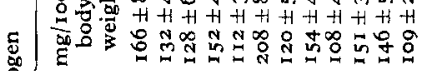

至.

$\infty$ \& $N$ D

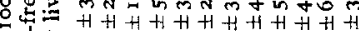

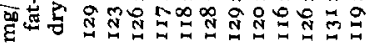

111111111111

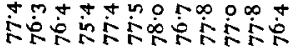

कृ

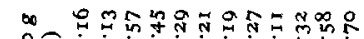

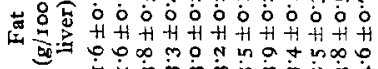

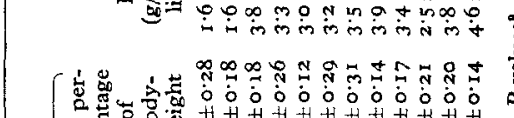

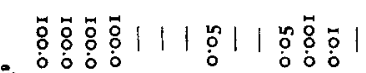

$-\dot{0}$

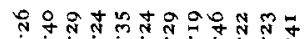

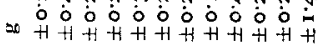

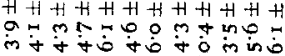

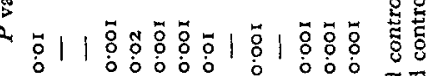

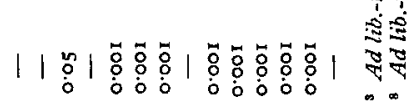

sol

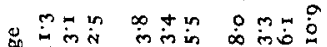

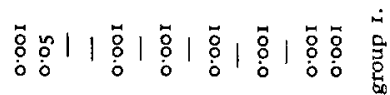

3

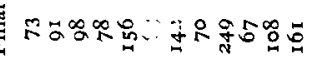

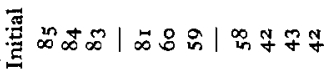

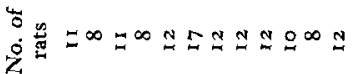
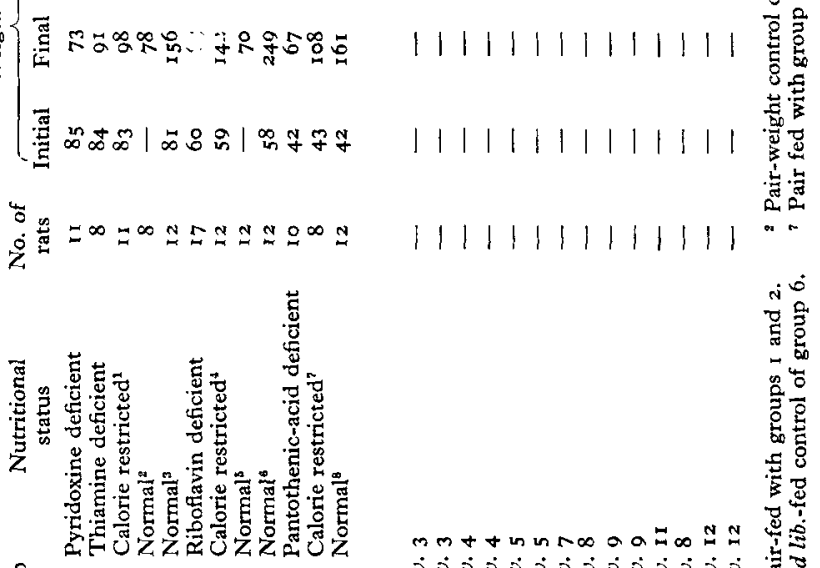

옹용
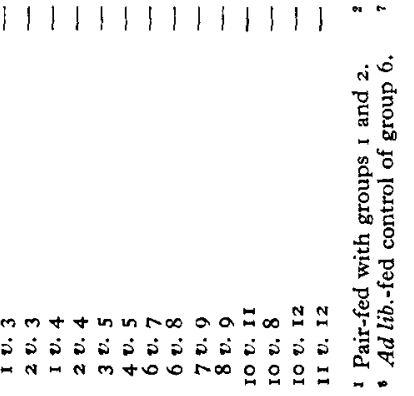


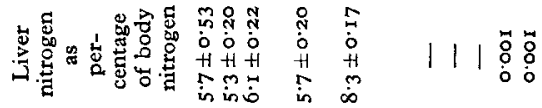

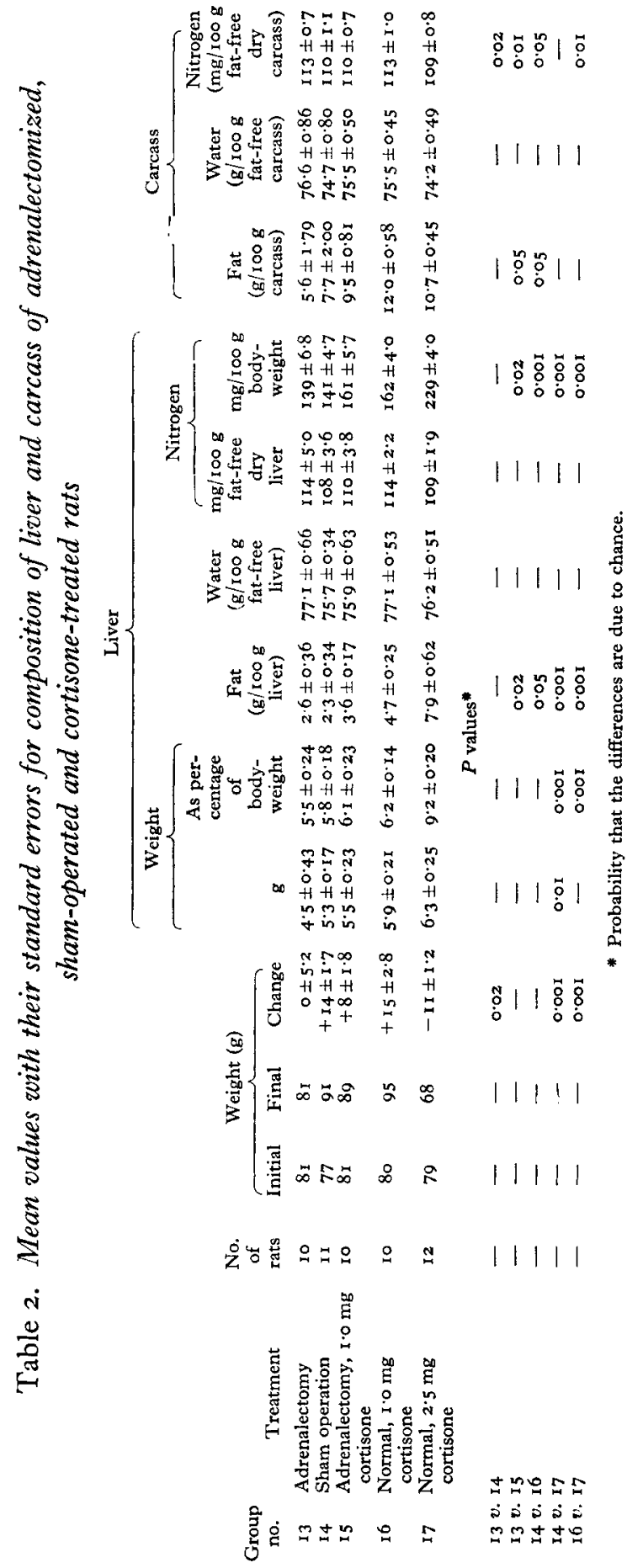


It is noteworthy that both livers and carcasses of deficient and control rats contained similar amounts of water/g fat-free tissue and of nitrogen/g fat-free, dry mass. There were statistically significant differences in the nitrogen contents of the carcasses, but they appear to be hardly important, since they never exceeded $7 \%$ of the total.

\section{Effects of adrenalectomy and cortisone treatment (Table 2)}

Five groups of rats were studied. Rats of the first group (13) were adrenalectomized; their weights did not change during the 8-10 days after operation. The second group (14) served as controls, the rats being sham-operated. Their average weight increased by $14 \mathrm{~g}$ after operation. Rats of the third group ( 15 ) were adrenalectomized also and daily injected with $\mathrm{I} \cdot 0 \mathrm{mg}$ cortisone. The mean weight increased by $8 \mathrm{~g}$. Groups $\mathrm{I} 6$ and 17 were normal rats receiving daily injections of $\mathrm{I} \cdot 0$ and $2.5 \mathrm{mg}$ cortisone, respectively. The weight of group 16 increased by $15 \mathrm{~g}$, whereas that of group $\mathrm{I} 7$ declined by I I $g$ during the 8-10 days observation period.

The livers of rats receiving $2.5 \mathrm{mg}$ cortisone were significantly enlarged, whereas those of the adrenalectomized animals were normal. Cortisone treatment, even with relatively small doses, increased the amount of liver nitrogen per unit body-weight. However, only large doses effected a significant shift of body nitrogen to the liver. Adrenalectomy had no effect on either liver or carcass fat. Cortisone increased liver fat and, in small doses, carcass fat too. Large doses of cortisone, which cause a decrease in body-weight, apparently prevent fat accumulation in the carcass.

Neither adrenalectomy nor cortisone treatment had any influence on the concentrations of liver and carcass water/g fat-free tissue. Similarly, nitrogen concentrations/g fat-free, dry liver and carcass remained unaffected by changes in adrenal activity.

\section{DISCUSSION}

Our results show that dietary lack of certain B-vitamins led to changes in the body composition of rats. The liver was much enlarged in riboflavin deficiency, less in deficiency of pyridoxine or pantothenic acid, and was of normal size in thiamine deficiency. Since it always contained similar amounts of nitrogen/g fat-free dry tissue, a greater percentage of total body nitrogen was shifted to the liver of rats deficient in riboflavin, pyridoxine or pantothenic acid than to those of ad lib.- or pair-fed controls of the same age. A comparison with control groups maintained on the supplemented basal diet given ad lib. (groups 8, 4, 5, I2, 9) showed that with increasing age and weight $(70,78,156,161,249 \mathrm{~g})$ there was a decrease in the relative liver weight $(6 \cdot 1,6 \cdot 0,3 \cdot 9,3 \cdot 8,4 \cdot 4 \%$ of body-weight), in the liver nitrogen per unit body-weight $\left({ }_{54}, 1_{5} 2,112,109,108 \mathrm{mg} / 100 \mathrm{~g}\right.$ body-weight) and, therefore, in the percentage of body nitrogen in the liver $(5.7,5.8,4.4,4 \cdot 5,3.7 \%)$. Pyridoxine- and pantothenic acid-deficient rats exhibited a distribution of body nitrogen more characteristic for their weight than for their age, and riboflavin-deficient rats had even more nitrogen in their livers than normal rats of similar weight. It is noteworthy that calorie deficiency (groups 3, 7, II) did not affect liver protein, thus confirming a previous report (Rosenthal \& Allison, 1956). 
Nitrogen metabolism in pyridoxine-deficient rats has already been studied. The liver weight was found to have increased (Olsen \& Martindale, I 954), but no alteration in the level of protein in liver (Beare, Beaton, Smith, White \& McHenry, 1953) or carcass (Beare, Beaton \& McHenry, 1953) has been noted. Other investigators (Ross \& Pike, 1956), however, have observed a higher nitrogen content of liver; since the liver was enlarged, there was also a much higher level per unit body-weight. These changes have been thought the result of an impairment in nitrogen metabolism due to lack of pyridoxine. Our studies demonstrate, however, that the observed increase in liver nitrogen is not the specific result of the pyridoxine deficiency and that it is accompanied by an abnormal distribution of body protein.

Fat content of carcass was uniformly diminished in all types of vitamin deficiency studied, whereas that of the liver was diminished in pyridoxine, thiamine and pantothenic-acid deficiency only. Since the deficient animals consumed the same amounts of food as the pair-fed controls, it follows that they utilized it less efficiently. A decrease in the economy of food utilization has already been described as a result of dietary lack of riboflavin (Sure \& Dichek, 194I) and of pyridoxine (Sure \& Easterling, 1949).

In normal rats (groups $8,4,5,12,9)$ carcass fat increased slightly with increasing body-weight ( $\left(3^{\circ} 7, \mathrm{I} I \cdot 6, \mathrm{I} 2 \cdot 1, \mathrm{I} 4 \cdot 9,19 \cdot 4 \%\right.$ ), liver fat remaining more or less constant. Restriction of food intake induced a depression of weight rather than of deposition of fat. Carcass fat of groups 3 , I I and 7 , which had mean weights of 98 , 108 and $142 \mathrm{~g}$, amounted to $9.2,10.2$ and $14.5 \%$ respectively. It has already been shown by Ashworth \& Cowgill (1938) that older rats, and hence rats of larger body-weight, tend to contain a greater percentage of fat than younger and smaller animals, which seems to hold true also for rats restricted in food intake.

Our figures provide additional proof of the well-established fact that the water content of the body decreases with increasing fat content and that its concentration in the fat-free mass remains remarkably constant (Ashworth \& Cowgill, 1938; Spray \& Widdowson, 1950). No appreciable deviation from normal water concentration was noted in our vitamin- or calorie-deficient rats. This constancy of water content does not preclude the possibility of a temporary water retention and a delayed diuretic response after a water load in the above recorded nutritional disorders (Guggenheim, 1954a, 1954 $b$; Guggenheim \& Diamant, 1955).

Cortisone treatment of both adrenalectomized and normal rats increased liver weight and liver protein, leading to a distribution of body protein similar to that in rats deficient in riboflavin, pyridoxine or pantothenic acid. In contrast to these rats, however, cortisone increased liver fat considerably and, with small doses, carcass fat. Similar effects of cortisone have been described by Silber \& Porter (1953). Stimulation of the adrenals seems, therefore, not to be the cause of the abnormal distribution of body protein in these particular vitamin deficiencies.

\section{SUMMARY}

1. Composition of liver and carcass has been studied in rats suffering from deficiency of pyridoxine, thiamine, riboflavin or pantothenic acid and compared with that of ad lib.-fed, pair-fed and pair-weight controls. 
2. The liver was considerably enlarged in pyridoxine, riboflavin and pantothenicacid deficiency, but was normal in thiamine deficiency. In the three first deficiencies it contained more nitrogen per unit body-weight and a higher percentage of body nitrogen than in ad lib.- and pair-fed controls.

3. Relative size of liver, nitrogen level and percentage of body nitrogen in the liver of rats severely restricted in calorie intake were similar to those of $a d$ lib.-fed rats.

4. Carcass fat was uniformly diminished in all types of vitamin deficiency studied, whereas liver fat was reduced in pyridoxine, thiamine and pantothenic-acid deficiency only.

5. There was no appreciable deviation from the normal in water content of fat-free liver and carcass or in nitrogen concentration of fat-free, dry liver and carcass.

6. Cortisone-treated rats had larger livers with increased nitrogen per unit bodyweight. In contrast to vitamin-deficient rats, their livers contained more fat than normal. The abnormal distribution of body nitrogen in these particular vitamin deficiencies is, therefore, unlikely to be the result of adrenal stimulation.

Generous gifts of galactoflavin from Merck and Co., Rahway, N.J., and of the calcium salt of $\omega$-pantothenic acid from $\mathrm{Dr}$ Stekol, Philadelphia, are gratefully acknowledged. We are indebted to $\mathrm{Mr}$ Y. Fattal for his valuable technical help.

\section{REFERENCES}

Ashworth, U. S. \& Cowgill, G. R. (1938). F. Nutr. 15, 73.

Beare, J. L., Beaton, J. R. \& McHenry, E. W. (I953). F. biol. Chem. 202, 589.

Beare, J. L., Beaton, J. R., Smith, F. I., White, J. M. \& McHenry, E. W. (1953). Amer. F. Physiol. r75, 2 I.

Clark, J. H. Jr. \& Pesch, L. A. (1956). F. Pharmacol. 117, 202.

Eisenstein, A. B. (1957). Endocrinology, 60, 298.

Ershoff, B. H. (1952). Vitam. Eீ Horm. ro, 79.

Forker, B. R. \& Morgan, A. F. (1954). F. biol. Chem. 209, $3 \circ 3$.

Guggenheim, K. (1954a). Endocrinology, 55, 156 .

Guggenheim, K. (1954b). Metabolism, 3, 44.

Guggenheim, K. \& Diamant, E. J. (1955). F. Nutr. 57, 249.

Guggenheim, K. \& Halevy, S. (1958). Int. Z. Vitaminforsch. 28, 301.

Morgan, A. F. (195I). Vitam. E Horm. 9, I6r.

Olsen, N. S. \& Martindale, W. E. (1954). F. Nutr. 53, 329.

Rosenthal, H. L. \& Allison, J. B. (1956). F. agric. Fd Chem. 4, 792.

Ross, M. L. \& Pike, R. L. (1956). F. Nutr. 58, 25 I.

Silber, R. H. \& Porter, C. C. (1953). Endocrinology, 52, 518.

Spray, C. M. \& Widdowson, E. M. (1950). Brit. F. Nutr. 4, 332.

Sure, B. \& Dichek, M. (1941). F. Nutr, 21, 453.

Sure, B. \& Easterling, L. (1949). F. Nutr. 39, 393. 